\title{
O VELHO, O ANTIGO E O NOVO \\ Um ensaio sobre a construção da antiguidade em objetos comercializados em antiquários em Porto Alegre, RS
}

Anelise dos Santos Gutterres

\section{Introdução}

O objetivo desta monografia é refletir a partir dos pressupostos antropológicos os processos que envolvem a compra e a venda de antiguidades na cidade de Porto Alegre. Para essa empresa, partimos de uma experiência etnográfica junto a um antiquário localizado no chamado "Caminho dos Antiquários"”, no Bairro Centro da capital. O investimento nessa experiência foi pensado a partir da hipótese de que haveria um conjunto de valores que distinguiriam a definição do que é um objeto e do que é uma antiguidade. Preocupações guiadas pelo trabalho de Eric Hobsbwan na sua obra A Invenção das Tradições (1984).

Para pensar a relação de troca operada na compra e na venda, seguimos as reflexões de Marcel Mauss no seu Ensaio sobre a Dádiva, onde partindo da idéia do hau, o espírito que mantém as relações de troca na sociedade maori, possamos pensar a partir dos espaço dos antiquários, a construção da antiguidade não como previamente definida, e sim como uma categoria que é construída a partir da troca entre o comprador e o vendedor de antiguidade. Ainda provocados pela obra de Mauss, a partir do ensaio As Técnicas do Corpo procuraremos pensar que assim como a expressão do corpo pode revelar uma tradição, a construção da antiguidade também pode revelar alguns aspectos da distinção de classes sociais em Porto Alegre.

\footnotetext{
${ }^{1}$ Segundo o site da prefeitura de Porto Alegre: "O Caminho dos Antiquários é um projeto desenvolvido pela Prefeitura de Porto Alegre em parceria com a comunidade e é uma iniciativa que está inserida no Programa de Revitalização do Centro. Tem como objetivo valorizar o trecho que liga a Praça Daltro Filho à Praça Marquesa de Sevigné compreendendo trechos das ruas Marechal Floriano Peixoto, Demétrio Ribeiro, Coronel Genuíno e Fernando Machado. Esta região caracteriza-se pela grande concentração de estabelecimentos que comercializam antigüidades. O espaço, já repleto de lojas de antigüidades, foi transformado em uma grande feira a céu aberto que acontece todos os sábados". Site: http://proweb.procempa.com.br/pmpa/prefpoa/vivaocentro/default.php? p_secao $=98$
} 
O hibridismo cultural, conceito trabalhado por Peter Burke nos ajudará a pensar nas questões relativas à originalidade da antiguidade e no caráter intercultural implícito na sua construção. A discussão de cultura global trazida por Anthony Smith (1994) permeará o desenvolvimento da argumentação teórica, no sentido de ressaltar a permanência do desejo, na cidade de Porto Alegre da posse de objetos oriundos de Manufaturas Européias do século XVIII e XIX. Provocando-nos a pensar numa globalização de estilos de vida pré-era da “mundialização" (ORTIZ:1994) já que a circulação dessas antiguidades na cidade começa antes dessa época. A mudança de status que essas antiguidades propõem, ligadas a um compartilhamento desse mesmo estilo de vida fundado na crença da necessidade de "educação" (MAUSS, 2003:402) para que sejam apreciados, no permite pensar que mudanças estão em jogo visto que esses estilos de vida se sobrepõem na metade do século XX, a uma imagem de progresso, que ia propor novos parâmetros para definição do belo, do velho e do novo, orientada por novas ideologias que visavam o desenvolvimento, a construção de novas formas e a destruição das velhas (PAIVA, 1942).

Sobreviventes desse período, as antiguidades, assim como no seu local de origem, a Europa, continuaram sendo procuradas. Formando entre comerciantes, compradores, colecionadores uma "comunidade" que ultrapassa o território de origem $($ ORTIZ,1994) dessas peças. No sentido de promover o compartilhamento de uma mesma referência para sua apreciação, que ultrapassa os limites territoriais das nações. A partir dos processos migratórios iniciados no fim do século XIX, principalmente por uma imigração alemã de alto poder aquisitivo (GANS, 2004), aliados à industrialização crescente que contribuiu com a falência de uma aristocracia agrária e rural no estado, pode-se pensar a origem do volume de peças que hoje compõem o acervo de antiguidades das lojas de Porto Alegre.

Com o auxílio daqueles que se colocaram a disposição para responder ingênuas perguntas sobre o que era uma antiguidade, André e Aline, podemos perceber neste ensaio reflexões a cerca da invenção das tradições em torno desses objetos; os sentimentos que circulam entre os colecionadores deles; a definição sempre abstrata do que é novo, do que é velho e do que é antigo; a suposta "alma" que habita o interior de cada um deles.

Os dados etnográficos foram colhidos a partir do uso de procedimentos de entrevista com roteiro, observação direta, conversas não diretivas e etnografia de rua (ECKERT e ROCHA, 2005). Foram pesquisados, também, sites de associações e lojas ligadas a antiguidades no Brasil, museus e lojas de porcelana com sede na Europa. Também, a partir dos procedimentos de observação, foi acompanhada por alguns dias, a rotina de trabalho da loja O Mensageiro da 
Caridade $^{2}$, localizada na Avenida Ipiranga na cidade de Porto Alegre e da Feira de Antiguidades do Brique da Redenção.

\title{
Refletindo sobre a antiguidade, conhecendo o objeto, definindo o mercado
}

Com uma "idéia na cabeça" e alguns telefones na mão, a primeira tentativa de aproximação aos antiquários não teve uma recepção muito amistosa. No telefone com o proprietário de uma loja, localizada na mesma rua onde cerca de dez antiquários disputam por uma mesma clientela exigente, especializada e apaixonada, essa pesquisa foi enfaticamente desestimulada a prosseguir:

\begin{abstract}
"Eu acho que não tem nada a ver essa tua pesquisa. Não entendo porque tu quer fazer isso, eu não vou expor meu cliente, dizendo onde compro a peça. E eu ia ganhar o que te dando essa entrevista? Ainda ia perder tempo de dando atenção ao invés de dar atenção ao meu cliente. Eu não to interessado".
\end{abstract}

O diálogo com esse proprietário teve papel importante no redirecionamento do campo, no sentido do investimento em perguntas que não deixassem tantas dúvidas sobre que tipo de estudo era aquele que estava se propondo. De forma a tornar mais claro o lugar de onde era feita a pesquisa, explicitando que ela não estava interessada de modo algum em desvendar ou ter contato com a rede de vendedores no qual a loja estava inserida. Isso porque a partir dessa conversa foi ficando mais claro o contexto onde essas perguntas caiam e foi preciso redimensionar o trabalho a partir das categorias manipuladas nesse contexto. Este homem, que num primeiro momento desestimulou a continuidade do trabalho de campo, acabou sendo importante na reorientação e esclarecimento de alguns dados que não estavam contemplados nas preocupações iniciais de campo, mas que eram determinantes para a continuidade dele.

Em primeiro lugar: havia uma rede de compradores e vendedores muito fechada, que incluía famílias, comerciantes de antiguidades, lojas, impostos e exclusividades. Em segundo lugar: havia um mercado de antiguidades e um tipo de venda especializada e focada no atendimento da demanda de um único cliente por vez. Em terceiro lugar: havia uma desconfiança muito grande com quem era de fora e uma competição entre os que eram de dentro desse mercado. Pensando na linha dos trabalhos de Mauss, que afirma: "o mercado é um fenômeno humano que não é alheio a nenhuma sociedade conhecida" (2003: 188), podemos

2 Integrante do Secretariado de Ação Social da Arquidiocese de Porto Alegre, ligado a CARITAS ARQUIDIOCESANAS, o programa Mensageiro da Caridade recebe sob a forma de doação: objetos, móveis, computadores, eletrodomésticos, eletroeletrônicos dos mais variados tipos. Estes objetos depois de restaurados são revendidos na loja. Tendo como alvo principal pessoas de menor poder aquisitivo, hoje o "mensageiro" é pauta de matérias em programas sobre decoração, e recebe visitas de todo o tipo de pessoas, das mais variadas rendas, que vão à loja a procura de "achados", peças "retro" e objetos antigos. Segundo o site da Prefeitura de Porto Alegre o programa emprega hoje "mais de 120 jovens a partir dos 16 anos" que trabalham consertando os objetos com defeito que depois serão vendidos nas duas lojas localizadas na Avenida Ipiranga. 
refletir sobre o caráter universal do mercado como estruturador das sociedades. Nesse sentido a partir da categoria mercado, vamos observar quais são os valores trocados na compra e na venda dessas antiguidades, quais as especificidades desse mercado de antiguidades.

Os pressupostos levantados a partir dessa conversa ao telefone foram dias após esse ocorrido, levados para a proprietária da loja da frente, uma jovem de vinte e seis anos, exvendedora da loja, hoje sócia desse que é um dos comércios de antiguidades de mais confiabilidade no circuito de antiguidades do centro da cidade. Aline foi indicada por outra vendedora, de uma loja localizada na esquina da rua de cima. Ficou claro depois, que essa vendedora também já tinha trabalhado na loja que hoje Aline dividia com seu outro sócio, André. A partir disso, podemos observar uma rotatividade entre os vendedores das lojas de antiguidades como uma característica importante deste mercado já o ritmo das admissões e das trocas de hierarquias dentro da loja respeita o ritmo da entrada e saída das peças. Um ritmo que também define a abertura e o fechamento das lojas. Uma lógica baseada na confiança, na tradição dentro do mercado e na mudança das mesmas pessoas dentro da rede dele.

"Até porque assim eu tive muita dificuldade no começo, eu comecei a trabalhar com o André eu tinha dezenove anos. E ai, então, as pessoas entravam e olhavam: e o que essa guriazinha sabe, né? Nada! É então, a questão da credibilidade, da confiança. Depois de sete anos que isso começou, assim, que hoje em dia eu tenho meus clientes, eu posso sentar e conversar contigo e dizer exatamente o que acontece, uma pessoa vai entrar aqui e eu vou dizer com propriedade isso é um mármore italiano, isso é... Tem hoje em dia confiança no que eu falo" (Aline)

O tempo da formação de um especialista em antiguidade conta para aquele que vai comprá-la e conta para aquele que vai vendê-la. A garantia de que aquele objeto é genuíno, que o estado está perfeito, se foi restaurado ou não, qual o material usado, a que época histórica - escola ou estilo - ele pertence; são informações que são passadas pelo vendedor. A confiança nele é a confiança na loja, é a confiança no valor do objeto que será comprado.

\section{$O$ vendedor de antiguidades}

A partir do relato de Aline que reforçará a categoria "outro mundo" para descrever a ambiência da loja de antiguidades, ressaltando que ela não teve uma trajetória social integrada a uma família de colecionadores, como a maioria dos proprietários das lojas da região ${ }^{3}$, podemos começar a delimitar limites de classe social e estilo de vida como relevantes na busca pela

\footnotetext{
${ }^{3}$ Pelo que pude perceber, os proprietários eram na maioria colecionadores de antiguidades antes de serem comerciantes de antiguidades. Pareceu-me um requisito para entrar no mercado: ser colecionador, ou pertencer à família de colecionadores, ou à família de comerciantes de antiguidades, como é o caso de André. Brenda, dona da loja da esquina, onde trabalha Gisa, vendedora que me indicou o contato de Aline, abriu uma loja funda e de dois andares somente com as peças da sua coleção. Segundo Aline ela teve sucesso porque fazia parte de uma rede de leilões, de uma rede de compradores, porque teve muita dificuldade, mesmo sendo colecionadora, de no início se inserir no mercado de antiguidades.
} 
definição daquilo que é considerado uma antiguidade. O "outro mundo" da loja de antiguidades tem um ritmo lento, de poucas e valorosas vendas, onde a qualidade da relação da troca é fundamental no sucesso do negócio. Falando das sociedades que nos precederam, no início do seu Ensaio Sobre a Dádiva, Marcel Mauss irá dizer que "antes da instituição dos mercadores, e antes de sua principal invenção, a moeda propriamente dita", antes das formas modernas do contrato e da venda, que envolve a moeda oficial, poderíamos ver como a moral e a economia regiam essas transações. Portanto para Mauss a moral e a economia mesmo com o advento da moeda, continuam estruturando as sociedades a medida de que essas representações da moral e da economia, para ele são "a rocha humana sobre as quais são construídas nossas sociedades" (MAUSS, 2003:189). Esse pensamento de Mauss é importante para pensarmos o caso das antiguidades, onde a moral que estrutura a troca explícita na compra e na venda de uma peça está representada na confiança. É a partir da confiança que esse acordo entre-mundos é feito.

É uma grande quantidade de dinheiro que move este mercado de antiguidades, porém, o dinheiro valoriza mais quem compra do que quem vende. Pensando no sentido da disposição de pessoas com alto poder de aquisição ser proporcional a determinação da cotação de preço para uma peça específica, vemos que o mesmo não se aplica a medição do conhecimento de antiguidade. Uma pessoa com dinheiro não necessariamente é uma pessoa com conhecimento de antiguidade ou uma pessoa "que entende de antiguidade". Ter dinheiro vale menos do que ter status de entendedor. $\mathrm{O}$ vendedor, que geralmente pertencente a uma classe média baixa nesses casos, por essa lógica do status (BOURDIEU,2007), é alguém que vale muito nesse mercado, muito mais do que a classe lhe permitira valer. Geralmente por gostar de antiguidade ou ter disposição para adquirir o conhecimento sobre os objetos e as pessoas que circulam na loja e no mercado, o vendedor acaba adquirindo status de colecionador. Um sujeito que trabalha na maioria das vezes sozinho, rodeado de dezenas de lustres; porcelanas com duzentos anos de idade; cristais; aparadores; quadros; bustos; santos; ânforas de diferentes épocas e procedências, no momento que é abordado por um comprador - ou um grupo deles - é como se assumisse a posse dessas peças, e falasse a partir delas. O vendedor adquire nessa hora o status de conhecedor, o status de colecionador daquela quantidade de objetos. E isso garante a venda.

A igualdade de conhecimento não depende da classe social ou às vezes nem da faixa etária de quem vende. Há algo que é trocado no momento da interação, que iguala esses diferentes "mundos" e garante o sucesso do negócio. Uma das razões confessou Aline, para ela ter se tornado sócia da loja, foi a presença constante dela no atendimento as pessoas, a confiança que os compradores foram tendo nela. Talvez uma estratégia de venda do ex-dono, que mais antigo no mercado, tinha consciência daquilo que envolve a busca por uma antiguidade. 
"É um outro mundo, antiguidade é um outro mundo, completamente fora. Engraçado, eu fiz, eu cheguei a fazer três anos de história, os dois últimos eu diminui as cadeiras, e era um conflito tão chocante de mundos, era tão conflituoso aquilo para mim. Porque tu vai, tu estuda na UFRGS tu sabe como é que é, ta ali no mundo acadêmico onde tu quer lutar por igualdade, tu quer, ainda mais história tu quer mudar o mundo. Assim né, todo mundo revolucionário, ninguém quer saber de marca, de compra, de nada, só que meu mundo é esse, eu vivo com pessoas que o salário de um ano, de uma família é uma peça que vai levar para casa sabe, onde normalmente as pessoas que trabalham não precisam trabalhar, as pessoas não trabalham para comer... mas um outro mundo assim, de motorista, de viagem, de festa, não é aquele mundo... E eu como ãh, hoje em dia não, mas assim como a sociedade é muito recente, mas eu era funcionária aqui, aquele mundo que a gente sabe que o mês acaba, o salário acaba primeiro que mês, né”.

\section{A antiguidade da antiguidade}

Conforme o antropólogo Gilbert Durand, em sua obra As Estruturas Antropológicas do Imaginário (1984), o imaginário exige que os contraditórios sejam pensados numa síntese. Portanto, quando irá falar de história, falará de uma síntese histórica, ou seja, uma história que contempla os estilos e as formas de pensamento de todos os povos no tempo. Aderindo a essa linha de interpretação - como forma de pensar como os povos organizam suas ações e transformações no tempo - podemos pensar a construção da antiguidade para as peças vendidas nos antiquários como oriunda, de mais uma das construções históricas possíveis e imaginadas pelo homem. Pensando dessa forma podemos compreender melhor o que é agenciado por quem adquire uma antiguidade dentro das representações da história ocidental, da história da nobreza, da história da riqueza. Representações que esses sujeitos percorrem na construção de uma explicação para o valor de antiguidade desses objetos.

$\mathrm{Na}$ relação entre representações de classe e de história, retomamos a noção de "hibridismo cultural" (BURKE, 2003) para pensarmos que as peças de porcelana de uma das mais famosas manufaturas ${ }^{4}$ européias e que hoje são concorridas entre os colecionadores de antiguidades, foram criadas do meio para o final do século XVIII por artesões que a fim de

\footnotetext{
${ }^{4}$ Manufatura é como são chamadas as grandes empresas de produção de porcelana, surgidas no século XVIII na Europa. Antes disso a Companhia das Índias comercializava a porcelana que era tão admirada que chegou a levar o nome de "ouro branco" (Guarisse, 2002:18). "A fina textura, ausência de porosidade, dureza e sonoridade já a distinguem a primeira vista da louça". O desafio das manufaturas foi primeiro descobrir, depois criar e guardar a salvo a técnica de mistura e queima da porcelana, que garantia a qualidade e a beleza da peça. Concorrentes entre si, as manufaturas - todas instaladas em grandes castelos - surgiram por toda a Europa e tinham características que garantem a peculiaridade de cada uma delas, como o tipo de azul, a mistura de cores, os temas esculpidos, a forma, o brilho. Essas especificidades são o deleite de um colecionador. A manufatura de Meissen, foi a primeira a ser criada, em 1710, depois foi a vez da criação da Manufatura de Viena, de 1719. A Manufatura de Sèvres, localizada na França é de aproximadamente 1753. Segundo André, depois veio a Manufatura Wedgwood, que é de 1759. Também muito prestigiada a porcelana criada por Philipp Rosenthal começa a ser manufaturada em 1879. Hoje as manufaturas possuem sites com vendas on-line e exposição de produtos novos assinados por designers renomados. Todos os sites possuem uma seção destinada a acervo ou histórico da manufatura. As porcelanas vendidas são vendidas para as mesmas funções de antigamente, para servirem como coberta de mesa (jogo de chá ou jantar) e decoração.
} 
manter o segredo da manufatura e principalmente da composição das cores para as porcelanas, "trabalhavam quase como prisioneiros" (GUARISSE, 2002:26). Portanto esses objetos com estatuto de arte, foram feitos por artesões que na época do "antigo regime" (HOBSBAWN,1996) não tinham nenhuma possibilidade de troca de posição dentro da hierarquia, a exemplo do que anuncia Bourdieu quando analisa a estrutura de ensino a partir dos ritos de instituição (BOURDIEU, 1998). A maioria as antiguidades vendidas nas lojas de antiguidades remetem a essa época de pré-revolução francesa. "Um mundo" que é compartilhado por intermédio de alguns fragmentos que evocam essa época. A partir da fala de Aline podemos reconhecer esses fragmentos pelos nomes das manufaturas: Meissen, Baccarat, Sèvres. Nomes que para ela e para o grupo colecionador de antigüidades, reúne em torno de si imagens de nobreza, glamour, beleza, arte, história. Evocando sentimentos que são compartilhados pelas pessoas à medida que elas entendem o mundo por intermédio dessas "chaves".

\begin{abstract}
"Mas o que acontece, quando tu entra nesse mundo, tem coisas chaves, por exemplo, essa ânfora do meio, de porcelana azul, isso é uma ânfora de Sèrvres ${ }^{5}$. Sèrvres foi uma manufatura da frança que quem iniciou ela foi o Luiz XIV para fazer aquelas coisas que ele gostava, ostentar... Então assim a antiguidade une muitos fatos históricos. Então, se tu tem grana, tu vai viajar, se tu vai viajar tu vai no Palácio de Versailles. Vai chegar no Palácio de Versailles tu vai ver milhões de lustres que nem esse, milhões de ânforas que nem essa, de tudo que é tamanho, então tu já vai agregar isso, né. Então quando tu chegar num antiquário tu vai saber que aquilo que tu viu tava na França. "Ah, que lustre é esse?" Tu vai me perguntar e eu vou dizer, "Ah é um lustre Versailles". Ah, eu já tive em Versailles os lustres são exatamente assim... Tem toda essa carga e as coisas remetem a isso. Tipo porcelana Rosenthal, porcelana Meissen, cristais de Baccarat ${ }^{6}$; são todos nomes de manufaturas, e essas manufaturas quando tu viaja são muito citadas, muito fortes, ainda mais porque a Europa é muito né, no sentido da antiguidade eles são muito mais apurados do que nós". (Aline)
\end{abstract}

Para o colecionador e vendedor de antiguidades, André Guarisse, em seu livro Antiguidades Européias: "as antiguidades são reflexo de um ambiente no qual está inserido o homem". Um homem que assim como ele está intrigado com a possibilidade de execução de certas manufaturas, onde a "tecnologia era limitada, transporte era precário e não havia energia elétrica". Na continuidade do texto como resposta a intriga ele lança uma antítese: esses povos, ou essas épocas tinham mais "tempo". O tempo que fala André parece ser o tempo da contemplação, do trabalho manual, dos pequenos detalhes, um tempo que: "em contradição ao tempo do nosso mundo corrido, globalizado e massificado" pode nos ajudar a pensar na imagem de um valor para antiguidade, que certamente é compartilhada por esses admiradores e

\footnotetext{
5 “Ter um objeto de Sèrvres tornou-se um dos mais altos símbolos de sofisticação e nobreza”. (Guarisse, 2002:22)

6 "Since it was established in 1764, Baccarat has continued expanding its influence, inspired in roots stemming from an ingenious handcrafted work of the highest quality, throughout the world. The creations of great artists inspired by the magic of crystal are all magnificent stones brought together into building the Art de Vivre collection. This is how Baccarat perpetuates the great French tradition of a cosmopolitan art of living. Envisioned by Philippe Starck, the Baccarat House in Paris, home to the brand's headquarters, is a meeting place for its most beautiful creations - and one of its most beautiful manifestations". Trecho retirado do web site dos Cristais Baccarat.
} 
colecionadores fazendo com que se identifiquem entre si. Seguindo a linha de Gilbert Durand, podemos pensar essas contradições trazidas na escrita de André - contradições de época, de estilo de vida, de condições de vida, de ritmo - como contradições que constroem uma narrativa que irá culminar no sentimento/essência daquilo que André chama de "alma de colecionador de antiguidades" (GUARISSE, 2002:9).

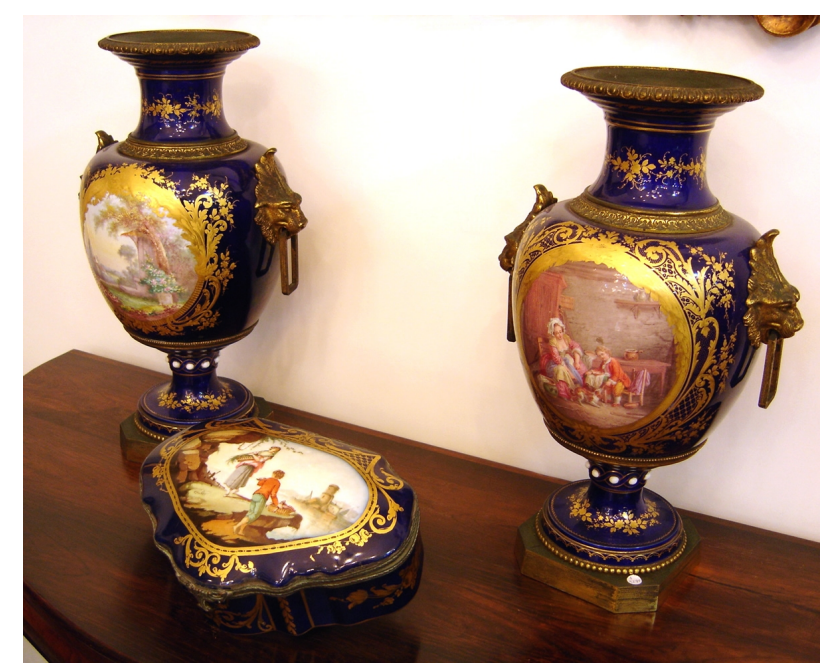

Fig. 1

Pelo conhecimento vindo do campo da arte (OSTROWER, 2004) dos fatos ocorridos no século XVI, podemos dizer que a porcelana chinesa foi a pioneira na concepção da técnica e construção dessa variação da cerâmica. Alcançando uma difusão que atingiu, por via das navegações, todos os continentes. Esse dado é relevante para pensarmos no sentido de que as porcelanas mais conhecidas e as que mais são buscadas pelos colecionadores no antiquário de Aline e André, são Européias. Indicando-nos a desconfiar de uma vontade de identificação e de uma aproximação do status de europeu como elemento integrante dessa "alma de colecionador de antiguidades" referida acima. No caso da porcelana, conforme Aline um dos itens mais colecionados e procurados nos antiquários de Porto Alegre sabe-se que a Europa investiu em porcelana mais de um século depois do Oriente. Portanto a antiguidade que estamos falando é uma antiguidade européia. E por esse intermédio que podemos refletir sobre o status requisitado e difundido da ligação de Porto Alegre com os costumes, tradições e ideologias européias. Um status que com essas antiguidades, reforçam a comunhão da cidade com o imaginário de uma certa Europa, de uma certa nobreza, de um certo "tempo".

\section{Sobre o velho e o antigo, a imagem do prestígio}

Segundo Hobsbawn (1996:9), na obra A Revolução Francesa "O resultado da Revolução Francesa foi o de que a era de Balzac substituiu a era de Mm. Du Barry". Nessa frase o autor 
consegue nos dois exemplos antagônicos, evocar uma série de imagens que nos aproximam do que foi essa quebra de regime: uma troca de imaginário. A Revolução Francesa se tornou importante nesse trabalho não pela evidente importância que ela tem na fundação de uma nova forma de organização social do ocidente, mas em como ela pode ser útil para pensarmos na relação da distinção que essa exigência de uma nova organização tornou visível. Ao escrever sobre a situação econômica da nobreza, Hobsbawn ressalta os privilégios que essa classe gozava pré-revolução.

“As 400 mil pessoas aproximadamente que, entre os 23 milhões de franceses, formavam a nobreza, a inquestionável "primeira linha" da nação, embora não tão absolutamente a salvo da intromissão das linhas menores como na Prússia e outros lugares, estavam bastante seguras". (HOBSBWAN, 1996:13)

Esse trecho nos leva a pensar, à medida que eram os nobres os maiores incentivadores (GUARISSE, 2002) da fabricação e usufruto das porcelanas, dos móveis, peças de decoração. Fornecedores de terminologias e ambiências para construção de estilos de arquitetura, arte e artesanato que são ainda difundidos e ensinados nas escolas de arte, como reguladores das definições e delimitações da origem ou influência das peças. Refletindo nesse sentindo, de como essas construções ainda dominam o imaginário do presente podemos pensar na construção de uma "coletividade" dessas "pessoas morais" (MAUSS, 2003:190), unidas pelas "mesmas imagens" (SMITH, 1994), mesmo que oriundas de histórias e culturas particulares. Partindo dessa reflexão, podemos tentar desenhar um movimento onde nobres fundadores de estilo, influenciam classes, que pela mudança de regime não podem mais receber essa nominação, porém compartilham da mesma condição de "primeira linha" e de valores parecidos com os de outrora. Valores que, podemos dizer, orientam a busca desses sujeitos pelas antiguidades como forma de se integrarem nessa coletividade que ultrapassa os limites das nações, mas compartilha uma mesma "cultura". 


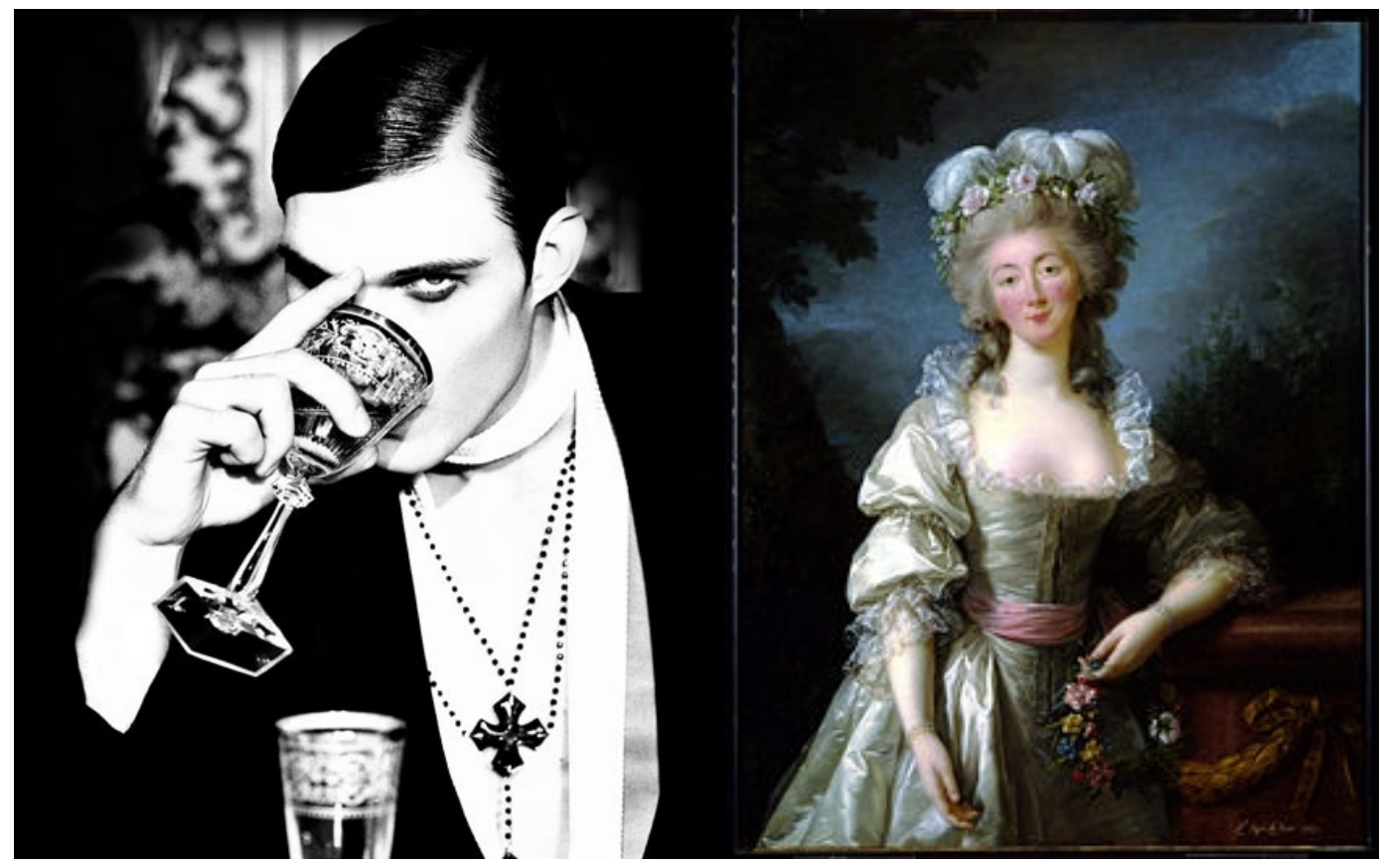

Fig. 2

Fig. 3

\section{A construção do prestígio}

Para dar conta da composição do que ele chamou temporariamente de "diversos", Marcel Mauss no seu ensaio As Técnicas do Corpo fará um esforço em esclarecer aquilo que ele supunha: poderia unir e diferenciar, numa observação da expressão corporal, diferentes grupos, épocas, origens e composições de sociedades diferentes. Falando de uma "maneira adquirida e não uma maneira natural de andar", Mauss estará falando da cultura como formadora das expressões e formas de movimentação do corpo. Ele descreve o Habitus (2003:404) como a palavra que melhor exprime hábito, no sentido do adquirido, no sentido da "faculdade de". Habitus para Mauss "não designa os hábitos metafísicos, a 'memória' misteriosa". Sua implicação era descobrir que a estrutura social contemplava a educação dos corpos, construindo formas de expressão e ação no mundo. Um corpo, pela sua expressão, revelava o contexto social em que estava uma pessoa ou o contexto social que queria se inserir, já que Mauss também observava o caráter de maleabilidade do corpo, no sentido de ser ele um instrumento da cultura.

"Esses 'hábitos' variam não simplesmente com os individuos e suas imitações, variam, sobretudo com as sociedades, as educações, as conveniências e as modas, os prestígios. É preciso ver técnicas e a obra da razão prática coletiva e individual, lá onde geralmente se vê apenas a alma e suas faculdades de repetição. (MAUSS, 2003:404) 
Chamando a atenção para as construções sociais, Mauss nos remete a capacidade humana que Hobsbawn (1984:271) irá enxergar como a faculdade de inventar tradições. Falando do período de 1870 a 1940 esse autor estará preocupado em observar "as invenções oficiais" que foram realizadas no decorrer desse período como forma de instituir nações. Hobsbwan ressalta a formação de grupos de pertencimento em torno de um mesmo sentimento compartilhado e evocado por um símbolo que por sua vez remete a um todo maior. Pensados pelo autor: a bandeira, o hino, a construção de rituais patrióticos foram eficazes para delimitação de um tipo de cidadão e criação um passado glorioso para os países ainda em formação. "Grupos sociais, ambientes e contextos sociais inteiramente novos, ou velhos, mas incrivelmente transformados, exigiam novos instrumentos que assegurassem ou expressassem identidade e coesão social e que estruturassem relações sociais" (1984:271). Com base nessas argumentações podemos pensar que essas antiguidades também estão envoltas na construção de uma tradição. Uma fabricação que passa pela definição das qualidades evocadas a partir da idéia de "alma". A "alma" como tradição compõem um mosaico que integra sentimentos de distinção, de gosto pela arte, de uma busca pelo sagrado. Que a partir do reconhecimento comum, forma grupo de colecionadores, de admiradores e amantes de antiguidades, os reunindo em torno dessa concepção de alma como aquela que funda o desejo deles por determinada peça antiga.

\section{A alma como tradição o outro mundo como o tempo}

Reunidos em associações locais e nacionais, são os antiquários: lugar e veículo, para a regulação, divulgação e manutenção dessa tradição. Segundo o site dos proprietários do antiquário Mercado Negro, também localizado no Caminho dos Antiquários:

\footnotetext{
"Na maioria dos países do mundo é considerada ANTIGA a peça com mais de 100 anos de idade. Peças do período Art Nouveau e Art Decó, portanto, não seriam consideradas ainda "antiguidades", por possuírem menos de um século de idade. Mas essas peças com muita freqüência formam o acervo de muitos antiquários por um conceito mais abrangente e flexível: é o fato da RARIDADE e peculiaridade das técnicas que foram empregadas na confecção das mesmas. São objetos cheios de arte, significados sóciopolíticos, culturais e afetivos e que, por isso, passam a representar e ter uma importância enorme como partes do patrimônio de um povo, país ou que marcaram profundamente uma época".
}

Pensando na construção da antiguidade em torno da idéia de alma, uma categoria que é intrínseca a troca e a interação entre o comerciante e o comprador é importante observar que as palavras usadas acima na definição de antiguidade remetem a idéia de unicidade e de espiritualidade. Elas tendem a se concentrar na origem, na idéia de um tempo passado, na 
valorização dos costumes extintos, na representação concreta de um "outro mundo". Neste trecho de descrição, a partir de diário de campo realizado em 18 de julho de 2008, podemos observar algumas conexões entre a "alma" e o "outro mundo". Trecho de diário de campo:

Numa tarde de sexta-feira, enquanto fazia uma das entrevistas com Aline, a campainha tocou e entraram pela porta da loja dois casais. Os homens tinham aparentemente, uns cinqüenta anos cada um, as mulheres, eram uns dez anos, mais novas. Eles circularam pela loja como cães farejadores treinados, como que a espreita de algo, a procura. Porém, olhavam com certa distância todos os objetos dispostos em cima dos aparadores, da moldura de lareira, das mesas de canto. Olhavam até com certo desprezo. Quando algo os evitava manter a distância, eles se aproximavam como num súbito, rapidamente juntavam o olho a peça e inevitavelmente a levantavam para verificar a existência de brasões na sua base. Conversavam entre si, sobre suas próprias peças e sobre as histórias de achado de algumas delas. Isso enquanto perguntavam a Aline especificidades como: "vocês têm copinhos Baccarat?" Os copinhos eram copos de servir licor só que sem "pé", Questão que Aline me respondeu depois.

O que me chamou atenção foi a forma como os homens se comunicavam entre esse vocabulário de $\operatorname{marcas}^{7}$ e de especificidades. A exemplo dessa: "copinhos". Era exigido que Aline soubesse exatamente que copinhos eram esses para que a possibilidade dele gastar algum dinheiro na loja se concretizasse. $\mathrm{Na}$ hora que entraram na loja um dos homens, o mais alto, caminhou rapidamente em direção a um biscuit ${ }^{8}$ de porcelana, todo branco, com motivos que lembravam celebrações germânicas. Como eu estava muito atenta a essa situação e era a primeira vez que entrava alguém na loja aquele dia para "olhar com tempo" as antiguidades, eu reconheci a peça, da visita que fiz na semana anterior. Quando esse homem entrou, essa foi a primeira peça em que ele parou na frente. Ele a olhou de cima e disse: "olha que peça bonita essa". Os dois continuaram pela loja, oscilando comentários e perguntas sobre outras peças e também sobre essa. "Ta inteira?" perguntou ele para Aline. "Gostei dessa peça", acrescentou enquanto virava as costas. Eles andaram mais um pouco dentro da loja, até que o homem resolveu perguntar o preço do biscuit, quanto custava a peça. Aline respondeu e houve uma longa e divertida negociação sobre o valor dela, até que finalmente ele acabou a levando para casa. O outro homem disse: "Não adianta, o Paulo gostou da peça, tem que levar, ele ta montando a coleção dele, se gostou tem que levar, não vai se arrepender". Parecia que ele falava isso para as mulheres e para o próprio Paulo, porém falava lá do outro lado da loja enquanto circulava, caminhando entre as estátuas da vitrine. Era uma espécie de comentário sobre a compra. Ao fim da venda, Aline me disse que eu estava dando sorte a ela. Que aquela era uma peça que estava ali há muito tempo exposta e nunca ninguém tinha gostado tanto. Pensei, que tudo bem, alguém sempre gosta mais de uma peça, o que tinha a ver isso com sorte? Então parei um pouco e quando Aline terminou de falar eu perguntei se ela por acaso percebia alguma "energia" sobre as peças. Se ela associava isso a compra, ou aos antigos donos. Então ela me respondeu:

' Engraçado tu perguntar isso. Sabe que tem gente aqui na loja que não entra né. Fica lá fora. Às vezes vem alguém aqui comprar alguma coisa e se a pessoa vem acompanhada tem gente que não consegue entrar, diz que tem uma energia muito forte aqui dentro. Teve gente que já desmaiou aqui, ali, ali atrás. Dizem que uma peça que os donos gostavam muito é difícil de vender. Sabe que tem um menino aqui ele tem uns dez anos, ele vem aqui com a mãe desde pequeno e ele adora antiguidade, adora, olha, pergunta, sabe mesmo. Então era perto do aniversário dele e ele veio com a mãe e disse, mãe no meu aniversário eu quero aquele lustre ali ó. E apontou assim qual era o que ele queria. Eu fiquei assim pensando uma criança de dez anos quer um vídeo game né, que criança vai querer de aniversário um lustre de cristal. Daí fiquei pensando nisso que tu falou, das peças. Eu acho que tem uma coisa sim, tem uma coisa nelas que eu não sei dizer o que é, mas eu sinto que tem. Aqui dentro tem' (Aline)."

\footnotetext{
7 "Sèvres tem sua marca, na qual podia identificar, já em 1753, quando ainda era Vincenes, o "L" cruzado dos Luíses, símbolos de Luís. No centro colocou a letra "A" para o ano de 1753, "B" para o de 1754 e assim sucessivamente até o " $Z$ " que corresponde a 1777. Um ano após, em 1778, a contagem foi reiniciada com um "A" duplo e finalizada em 1793 com um "PP". (Guarisse, 2002: 25)

${ }^{8}$ Segundo André Guarisse (2002: 25) o biscuit de Sèvres é um tipo de porcelana "sem vitrificar" que semelhante ao mármore branco de Carrara foi introduzida em 1751 por Jean Jack Bachelier. O biscuit tornou-se muito popular e chegou até às residências burguesas da época: "a produção de biscuit de Sèvres foi enorme. Fontes de inspiração procediam dos mais variados temas: danças, figuras dramáticas, festas, desenhos de pinturas era reproduzidos por Sèvres em suas famosas figuras brancas de porcelana sem verniz"
} 
O passado não vivido, representado pela antiguidade, a partir do consenso da alma que une os admiradores dela, ganha aqui nuances que nos levam a pensar na ligação que ela tem com o mundo fantástico no sentido de permitir a conexão com um passado tão antigo, que ela se torna a própria representação dele, a prova da existência dele e de certa forma de um desejo da sua conservação e da sua continuidade. Nesse caso estaríamos entrando no campo dos conceitos de memória, que neste trabalho não caberia problematizar. Porém é importante frisar que há uma diferenciação e uma relevância para o comerciante de antiguidades de que alguns objetos não possuem valor econômico, mas possuem um grande valor simbólico para o sujeito a quem esse objeto pertenceu.

"Eu só posso dar valor de antiguidade a algo que possa revender como antiguidade. Não tem valor no mundo que pague a lembrança evocada por um pequeno quadrinho comprado na viagem de bodas há setenta anos. Esse preço eu não posso vender, nem posso pagar”. (André)

São os objetos considerados "as coisas velhas". Aquilo que não faz parte do mercado de antiguidades então por isso o contexto que cria o seu valor não pode ser mensurado. Ao entramos nessas delimitações necessariamente teríamos que mergulhar com isso no universo dos conceitos de lembrança, pertença, memória familiar e herança, o que só será feito no contexto de uma dissertação de mestrado.

Fig. 4

Fig.5

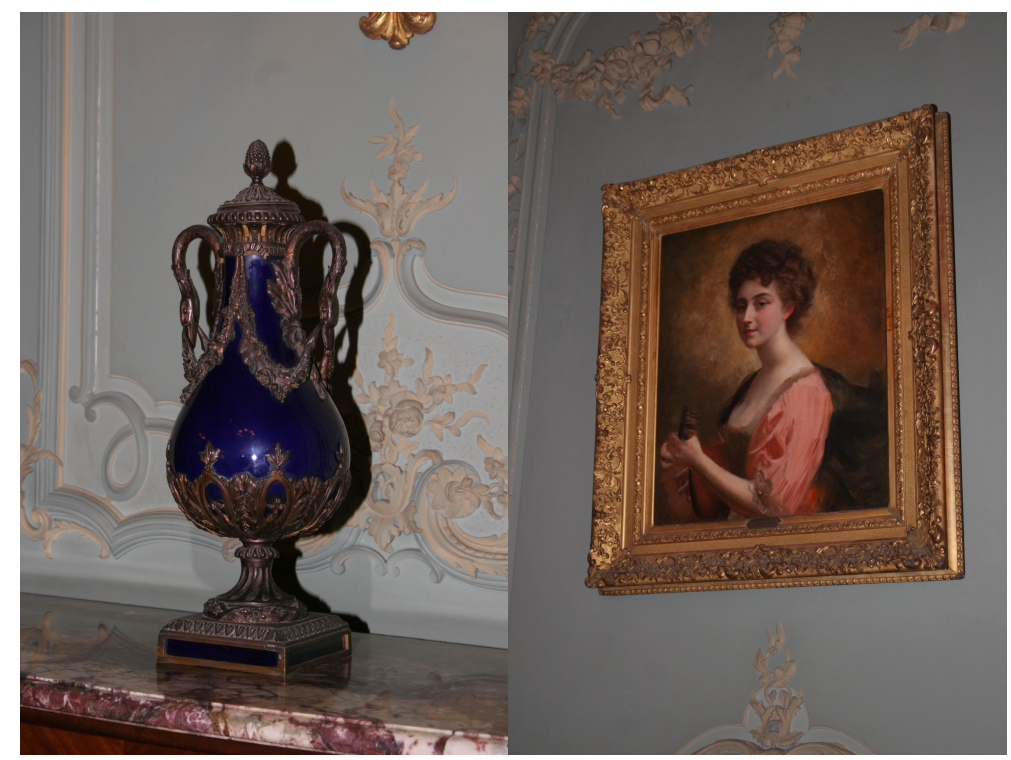




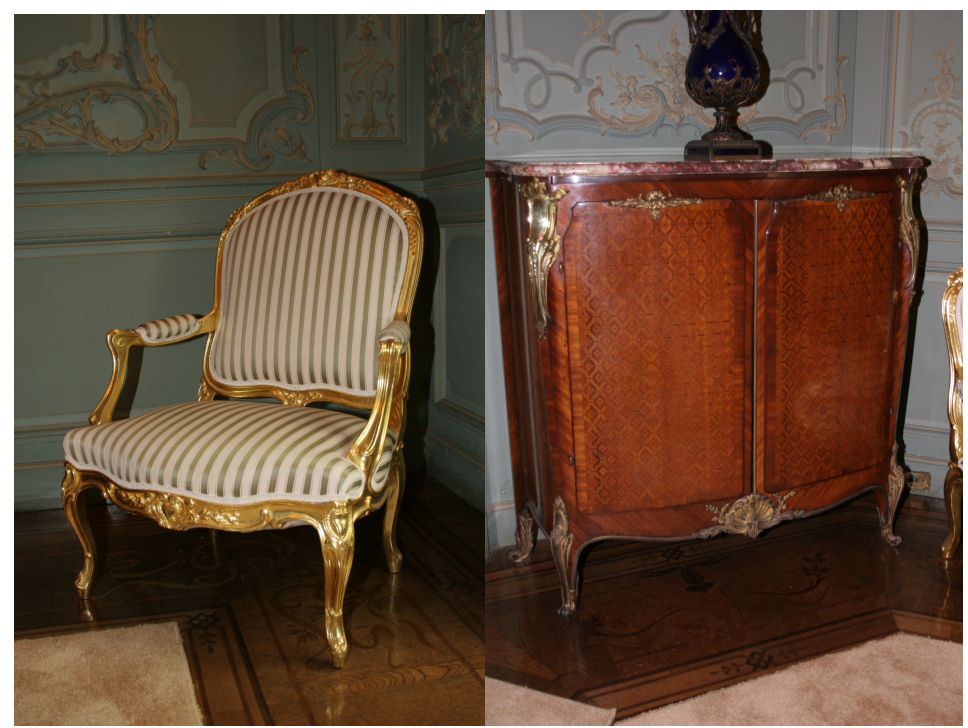

Fig. 6

Fig. 7

Móveis e objetos que integrariam um Fumoir original.

Palácio das Laranjeiras, Rio de Janeiro.

\section{O colecionador de antiguidades}

O colecionador de antiguidades é um colecionador de costumes do passado, em variações de formas e cores. É alguém que expõe sua peça, é alguém que a cuida, anseia pela parte que falta, visita a loja atrás daquilo que irá configurar o seu "quadro do passado". Maurice Halwbacks, em Memória Coletiva, irá falar nos quadros sociais da memória, dos enquadramentos da vida social que são resgatados por intermédio de um objeto, uma cena, um fragmento do passado capaz de reunir na sua existência todo um conjunto de práticas, de lembranças. Porém, não poderíamos dizer que o que move um colecionador são somente as memórias coletivas. Um colecionador como coloca Baudrillard busca um "objeto-paixão", e o busca para si. Na possibilidade de um pedaço dessa "memória coletiva", ser sua.

Pensado a partir da aquisição feita por Paulo, vemos que não são todas as antiguidades que apaixonam todo mundo, são algumas. É única a peça que encanta o colecionador, a que o chama, a que estabelece conexão com as representações que ele tem do passado. Baudrillard afirma na sua obra $O$ Sistema dos Objetos: "o objeto puro, privado de função ou abstraído de seu uso, toma um estatuto estritamente subjetivo: torna-se objeto de coleção" (2004:94). Para esse autor o objeto tem esses dois estatutos, o do uso prático e o da posse. E o sujeito duas categorias: o amador e o colecionador.

O sujeito colecionador possui a peça, ele briga, pede desconto, reserva, porque ele precisa possuir. O sujeito do uso prático está mais preocupado com a funcionalidade do que com 
o reconhecimento. Segundo o mesmo autor: "só uma organização mais ou menos complexa de objetos que se relacionem uns com os outros constitui cada objeto em uma abstração suficiente para que possa ele ser recuperado pelo individuo na abstração vivida que é o sentimento de posse" (Baudrillard, 2004:95). No entanto o colecionador de antiguidades, pela tradição da alma, não pode ser considerado somente um colecionador. Ele é uma amador e um colecionador.

"o prazer tanto em um como no outro, vem do fato de a posse jogar, de um lado com a singularidade absoluta de cada elemento, que nela representa o equivalente de um ser e no fundo do próprio indivíduo - de outro, com a possibilidade da série, portanto da substituição indefinida e do jogo" (Baudrillard, 2004:96)

A renovação, o jogo que se refere Baudrillard, da eterna procura acompanham a peça quando ela é buscada nos antiquários. Esses sujeitos são visitantes assíduos dos antiquários, vem sistematicamente observar a circulação, a possível chegada daquele copinho que completaria sua coleção, daquele objeto que irá despertar sua paixão. São sujeitos que querem ser encantados pelo espírito da troca. Segundo Aline, eles visitam toda semana a loja, ligam para ela para saber se chegaram "novas peças antigas", numa paixão que não é necessariamente nutrida por todos os consumidores de antiguidades. Aline aponta para uma diferença entre esses consumidores e estabelecendo uma distinção entre dois tipos ela mensura na representação de: ricos e novos ricos, o nível da qualidade da troca com esse consumidor, nos dando uma pista para pensarmos que se todos as peças tem uma "alma", a troca talvez seja o momento de desperta-la.

\footnotetext{
"Tem os novos ricos, né e os novos ricos, tem os que compram porque gostam, que é uma minoria, e tem os que compram porque o arquiteto disse para comprar. $\mathrm{E}$ às vezes nem vem na loja. Arquiteto escolhendo: hum hum, hum - Aline aponta o dedo para as peças - vira para mim e diz, 'manda para a casa do fulano'. 'Vamos botar no lugar' 'ficou bonito?' 'Ficou bonito na foto?' 'Então ta bom'

Não faz diferença se a peça foi feita há duzentos anos ou se foi feita ontem. Se tu entrar numa casa e souber o que é, ah que bom que tu sabe, tu vai achar que essa pessoa é super, com alto conhecimento da coisa, mas não é.

E eu já presencie isso aqui na loja, tipo o arquiteto assim: 'tu tem que ter um desse, um desse, um desse', a nível de ostentar mesmo. 'Mas porque que eu tenho que levar esse?' 'A porque fulano é isso e isso, isso, isso. Se tu tiver um...'

'Ah então eu quero!'

E vai ficar lá, se tu vai gostar ou não, não faz diferença”.
}

A relação entre o velho, o antigo e o novo, portanto, só pode ser medida pelo valor do objeto dentro de seu contexto. Se conforme Aline para o "novo rico" a antiguidade perde seu valor de antiguidade no momento que não faz diferença se ela o é ou não, chegamos num ponto onde poderíamos dizer que para uma peça ser antiguidade ela dependerá do compartilhamento de uma rede de valores, informações, conhecimentos, que agenciadas e trabalhadas no momento da 
compra e da venda construirão a "alma" do objeto, ou seja, sua tradição. . Uma alma que é dependente da troca, porque sem o conhecimento onde comprar, não há o encontro, sem a confiança na informação trocada pelo vendedor, sem o jogo da pechincha e da competição pela erudição não há a venda. O valor do objeto depende desses elementos para ser estabelecido.

\section{Considerações finais}

No jogo entre divisões e representações de classe, de conceitos de globalização, tradições e memória, as categorias de velho, antigo e novo irão estar sempre ligadas ao contexto dos grupos sociais (GEERTZ, 1989), e nesse caso ao contexto da troca. Uma "alma" que pode estar ligada a feitura, a forma peculiar como o objeto foi manufaturado, como coloca Ginzburg, na introdução de Queijos e Vermes: o valor de fabricação de determinado objeto é muitas vezes o valor do objeto; como um valor invisível, mas presente na impressão de um valor econômico gradativo, à medida que ele é passado adiante no tempo da cultura. Como pode estar ligada ao compartilhamento de um mesmo imaginário de uso dele, a quem pertenceu, por onde passou, qual a origem dessa antiguidade. Nos dois casos, o "tempo" será a alma evocada, e em torno dele que os objetos serão possuídos e amados. Quando a troca não tem hau, ela será somente compra, nunca posse. E a partir do caso trazido por Aline, dos compradores indiferentes à evocação do tempo da antiguidade, talvez ainda pudéssemos pensar num terceiro caso, que é quando os objetos são, como nesse exemplo, comprados para uma simulação. Uma simulação de posse e de paixão.

Segundo Bachelard, aqueles "centros de condensação da intimidade em que se acumula o devaneio" (2005:47) são aquilo que os objetos concentram em si, ou seja, que são capazes de representar e de evocar: uma lembrança, uma cena, uma pessoa. Nos dois casos, dos objetos, dos que tem preço e dos que segundo André, não tem preço, está presente a capacidade de reunir numa mesma peça, lembranças distribuídas durante, muitas vezes, uma ou mais vidas inteiras. Pois parece ser o que determinadas porcelanas, certos móveis, relógios, bibelôs, objetos tão importantes e tão cheios de destaque numa casa ou numa loja prontos para serem levados, têm. Se a raridade para os avalistas de peças antigas é um pré-requisito para a avaliação do preço de venda dela, não seria a raridade, então, essa possibilidade cada vez mais esparsa de experiência de um tempo que não se viveu?

O que esses objetos falam sobre a evidência de uma transformação: de costumes, usos e práticas que já não se fazem mais com o uso deles? A finitude, a possibilidade do esvaziamento de si, do seu mundo, das suas representações de mundo, talvez seja a chave para entender porque por valores diferentes em contextos diferentes certo objetos têm o poder de provocar um 
sentimento de pertencimento ao mundo que a partir da ligação com esse objeto é possível de ser vivido. Pensando a transformação dos costumes como ação a ser narrada a partir desses locais onde não se vende os objetos por seus antigos usos, mas por sua capacidade de evocação de um tempo findado. Podemos pensar esses objetos como "objetos possuídos”. Onde, numa casa ou num antiquário, eles sejam concentradores de uma evocação latente, que ultrapassado o limite da utilidade os faz uma possibilidade de narração de uma cultura.

\section{ÍNDICE DE IMAGENS}

Imagem 1 - Imagem retirada do site www.machadoantiguidades.com.br. Par de ânforas de porcelana de Sèvres. França séc. XIX. Med.: $46 \mathrm{~cm}$.

Imagem 2 - Imagem de abertura do site dos cristais Baccarat

Imagem 3 - Imagem digital de Pintura a óleo, retratando Mme. Du Barry

\section{REFERÊNCIAS}

BACHELARD, Gaston. A poética do espaço. São Paulo: Martins Fontes, 2005.

BAUDRILLARD, Jean. O sistema dos objetos. São Paulo: Editora Perspectiva, 2004.

BOURDIEU, Pierre. A distinção - Critica Social do Julgamento. Porto Alegre: Editora Zouk, 2007.

Edusp, 1998. A economia das trocas lingüisticas: o que falar quer dizer. São Paulo:

BURKE, Peter. Hibridismo Cultural. São Leopoldo: Editora da Unisinos, 2003.

CANCLINI, N.G. Culturas Hibridas. São Paulo: Edusp, 2006.

DURAND, Gilbert. As Estruturas Antropológicas do Imaginário. São Paulo: Martins Fontes, 2002.

ECKERT, Cornelia \& ROCHA, Ana Luiza Carvalho da. O tempo e a cidade. Porto Alegre: Editora UFRGS, 2005.

GEERTZ, Clifford. A interpretação das Culturas. Editora LTC, 1989.

GUARISSE, André. Antiguidades Européias. Porto Alegre: Editora Sulina, 2002.

GINZBURG, Carlo. O queijo e os vermes. São Paulo: Cia das Letras, 2006.

HALBWACHS, Maurice. A memória coletiva. São Paulo: Centauro, 2006.

HOBSBAWN, Eric. A Invenção das Tradições. Rio de Janeiro: Editora Paz e Terra, 1984.

. A Revolução Francesa. Rio de Janeiro: Editora Paz e Terra, 1996.

MAUSS, Marcel. Sociologia e Antropologia. São Paulo: Cosac Naify, 2003.

ORTIZ, Renato. Mundialização e Cultura. São Paulo: Brasiliense, 1994.

OSTROWER, Fayga. Universos da Arte. Rio de Janeiro: Elsevier, 2004.

PAIVA, Edvaldo Pereira. Expediente Urbano de Porto Alegre. Porto Alegre: Prefeitura Municipal, 1942

SMITH, Anthony D. Para uma cultura global. In: FEATHERSTONE, Mike (org.) Cultura Global; nacionalismo, globalização e modernidade. Petrópolis: Vozes, 1994.

Sites visitados

http://www.meissenusa.com/

http://www.antique-meissen.com/antique meissen_porcelain_dealer.htm 
http://www.buymeissen.com/

http://www.governo.rj.gov.br/palaciolaranjeiras_acervo/consultaacervo_local.asp?localiza=909

http://www.shoppingcidadecopacabana.com.br/port/lojas.html\#

http://www.machadoantiguidades.com.br/acervo/porcelanas.htm

http://www.baccarat-us.com/index.htm

http://www.int.rosenthal.de/1110/Company/History/1879-1900.htm

http://www.agantiguidades.com.br/site/conheca/index.php?id=168

http://lproweb.procempa.com.br/pmpa/prefpoa/vivaocentro/default.php?p_secao $=98$

http://www2.portoalegre.rs.gov.br/cs/impressao.php?reg=67217\&p secao=3\&di=2006-09-27 